Computer-Enhanced and Mobile-Assisted Language Learning:

Emerging Issues and Trends

\title{
The effect of feedback in teaching Thai as a foreign language
}

\section{The effect of feedback in teaching Thai as a foreign language}

\author{
Maliwan Buranapatana \\ Khon Kaen University, Thailand \\ Felicia Zhang \\ University of Canberra, Australia
}

\begin{abstract}
This chapter aims to explore the effect of providing multiple sources of feedback through a language teaching approach called the Somatically-enhanced Approach (SEA) (Zhang, 2006) in the teaching of Thai language to foreigners. Teaching innovations include: the use of relaxation techniques to relax students; the use of humming, clapping, mouthing, and physical gestures to emphasize the rhythm of the Thai language; the use of a Speech comparison tool (Sptool) for providing biofeedback; and the provision of all learning materials on CDs. Two groups of students were involved in the study. An experimental group (EG) consisted of 24 international students who enrolled in the Thai Language for Foreigners course at Khon Kaen University, Thailand. These students came from People's Republic of China, Vietnam, and Laos. They were taught using SEA. The control group (CG) consisted of 22 Chinese students who studied Thai language at Guangxi University for Nationalities, China, taught with the traditional method. The results of this study revealed that after 24 face-to-face contact hours over 8 weeks, international students who undertook a course in SEA spoke more fluently than the control group who studied Thai for 44 hours over 11 weeks. The differences in the quality and quantity of speech were statistically significant. The results of the study, both quantitative and qualitative, will be reported. The improved gains in students' performance in EG can be attributed to the multiple sources of feedback afforded by SEA.
\end{abstract}

\section{INTRODUCTION}

Receiving good quality feedback is an essential aspect of language learning especially at the beginning stages of learning a foreign language. Feedback is important because it is essential for teaching to be turned into learning and can play a significant role in students' development by providing the knowledge required for improvement (Hinett, 1998; Hyland, 2000). However, in order for the feedback to be effective, two objectives must be met: (1) to enable students to make sense of the feedback; and (2) to establish a common understanding of how this feedback may be implemented or acted upon by students(Fraser, 2001; Zhang, 2006).

In a language learning classroom error correction, body language, non-verbal behavior, facial expressions, gestures, and tone of voice are all used in communicating feedback. Such feedback is usually instantaneous, involuntary (from the feedback provider), episodic and disappears very quickly from the memory of everyone involved. The feedback we have just described ignore the 
learners' involvement in the feedback process. As far back as Morley (1994) stressed that new instructional design in teaching pronunciation should not only take into account of language forms and functions but also issues of learner involvement and learner strategy training. While this objective was achieved by asking students to reflect on their learning experiences in Vitanova and Miller's study (2002), this study adopts a different technique. We designed a learning environment for learning Thai as a second/foreign language in which students were actively involved in utilizing a range of strategies in their process of learning. In this way, students not only learned through receiving feedback from the teacher, they also learned to attune to their own bodies and listened to feedback from their own body. Another source of feedback was the use of a speech analysis tool (Sptool) (Zhang \& Newman, 2003) for offering audio and visual feedback and course data CD-Rom. This speech tool allows the incorporation of a visual representation of a student's production to be easily compared to the speech of a native speaker. We contend that the multiple sources of feedback obtained through the combination of various feature of SEA, Sptool and the dataCDrom will make the process of understanding and acting upon feedback $t$ easier and more accessible to students.

This chapter consists of the following sections: (1) a discussion of the theoretical framework that informs the study; (2) a discussion of the teaching context and method offering various forms of feedback;(3) a detailed description of the various features of the speech tool; and (4) results of a study involving a group of beginning foreign students learning Thai in a Thai and a Chinese university.

\section{THEORETICAL UNDERPINNING OF THE STUDY}

What happens to a beginner's perceptual system when one first starts to learn a foreign language? In the context of learning a foreign language, a person with normal hearing in his/her mother tongue will behave as though he/she were hard of hearing (Lian, 1980). Acoustically, each language sound carries all frequencies from about $50 \mathrm{~Hz}$ to about 16,000 Hz (albeit at various intensities). Theoretically, at any rate, each sound can be heard in many different ways. The ear seems to have a 'choice' as to what to hear in practice depending on the way the ear has been trained. L2 students tend to make 'choices' in the target language based on what they are familiar with in their mother tongue. Trubetzkoy (1939) refers to this as the mother tongue 'sieve'. For instance, a vowel is physically made up of a complex set of many frequencies produced simultaneously. When a vowel is heard, everything it contains is heard. However, when listening to a sound, it is not necessary to catch all the elements in order to recognize it as recognition only requires some of the sound spectrum. Each sound has a particular 'optimal' frequency (i.e. the frequency band, or combination of frequency bands) at which a native-speaker best recognizes and perceives the sound in question according to their mother tongue. Students who experience difficulty with a particular foreign language sound are considered as not having recognized (i.e. perceive) its optimum. Thus, they are unlikely to be able to reproduce the sound correctly. If, for example, the sound [i] in French is recorded and listened to successively through octave filters:

Figure 1. "L'appareil Suvaglingua, instrument de recherché et de correction phonétique”, R.P.A., 4, 1967, notes 13 and 14, pp. 62 and 63. Taken from (Renard, 1985)

Insert figure 1 here:=03_Zhang_figure1 
According to the Figure 1, the French [i] is made up of all those sounds, each sound occupying a different frequency. Yet when French speakers were asked to identify these sounds, all the sounds were identified by French speakers as productions of the phoneme /i/. This manipulation of the French [i] sound showed very clearly the superabundance of the acoustic reality. Through perception a distinction between what is necessary for [i] to be recognized ([i] is recognized between $3200 \mathrm{~Hz}$ to $6400 \mathrm{~Hz}$, previously in cps: cycles per second) and what is superfluous in the plethora of information which comes through the vocalic timbre (the quality of the vowel) was made by French Native Speakers (NSs).

However, when it comes to a L2 learner learning French, the learner would perceive a sound through hearing all the frequencies that are contained in a sound. As the learner's perception is likely to be mediated through the pre-established code based on his/her mother tongue, when it comes to perceiving a sound in L2, he/she is likely not to recognize the sound /i/ at the frequency recognized by a French person. He/she is likely to recognize the sound /i/ at a frequency dictated by his/her mother tongue such as between 300-600 Hz. Thus, he/she is in danger of confusing /u/ (between 300-600 Hz) with /i/ (between 3200 and $6400 \mathrm{~Hz}$ ), or with /o/ (between 400 and 800 $\mathrm{Hz}$ ) as these sounds also occupies part of the spectrum that contains /i/ at different frequencies. A remedial strategy could be, in order for L2 learners of French to perceive [i], to eliminate all the sounds at frequencies above $300 \mathrm{~Hz}$ and only leave frequencies between 3200 and $6400 \mathrm{~Hz}$ through a process of filtering so that L2 learners can be exposed to the French [i] at the correct frequency. This strategy is not very different from the strategy adopted by McCandliss, Fiez, Protopapas and McClelland (2002) in training Japanese speakers to discriminate between the difference between [r] and [1] in English in which exaggeration was used to highlight the difference.

A similar filtering process was used in the Verbo-tonal method (VTM) of phonetic correction, developed at the Institute of Phonetics of the University of Zagreb by the late Professor Petar Guberina. This method of corrective phonetics had been used by teams of teachers and researchers to write structuro-global audio-visual courses under the supervision of Professor Guberina and Paul Rivenc in the 1960s (Heras \& Regan, 1985; Renard \& Vlasselaer, 1976). Filtering in VTM (Renard, 1975) is a load lightening measure through which only the "relevant frequencies" for a particular sound, in this case, that of /i/ in French, is allowed to remain. Certain practices of SEA owe a great debt to VTM. These practices, derived in some part from VTM, provide an alternative approach to education in Thai tones and prosody through educating students in the performances of phrases in action. VTM does not and cannot offer students the complete mastery of the infinite diversity of the NS speech in any language because many aspects of language and language use of the Thai language or any other language have not been defined and may be not definable. Thus in the case of learning Thai as a foreign language, in this course L2 students were taught sentences which were most relevant to their lives in Thailand in particular ways so as to enable them to develop a 'feel' for the language. Students trained with the benefits of VTM might be better prepared to perform a phrase in such a way as to be more readily intelligible to NSs of the TL community.

In studies conducted for the rehabilitation of hard of hearing children and adult, SUVAG II machines (http://www.suvag.com/ang/produits/suvag_2.html) which are capable of transmitting language sounds at various frequencies including low frequencies without distortion (Guberina \& Asp, 1981) were used to bypass the mother tongue 'sieve'. In this particular study, the sentences that are fed through Sptool will have frequencies above $300 \mathrm{~Hz}$ removed through electronic filtering. So what is being displayed on the screen is the pitch curve (i.e. tones of Thai 
in this case) of the sentence to be learned. Though the same filtering technique was used to produce the sentences in the teaching materials, no recording of sentences at low frequencies was played in the classroom procedure because good quality amplifiers and loudspeakers were not available for this purpose.

Ideally, in order to sensitize student's perception to the tones of Thai, filtering should have been used to highlight the prosodic elements of the language. Due to the lack of such suitable equipment, instead of filtering, humming was used. The intonation pattern that is obtained through humming is a simulation of the original intonation pattern of the sentence. By humming, the suprasegmental aspect of the utterances is highlighted at the expense of the vowels and consonants. Humming allows students to focus on the suprasegmental aspect of the language. Since humming a sentence is within the capability of any normal hearing person, it is much more practical than the use of filtered sentences through loud speakers. Humming is but one of the procedures for exposing students to the corrective optimals of the Thai language.

After being exposed to corrective optimals through a number of procedures, it is through intensive articulatory practice that students can access valid acoustic models constituting the normal range for the phonemes of language. This course's intense language exposure via a variety of computer assisted tools, including the Sptool, plus the intensive articulatory practice carried out in Phase 1: language sensitization process, provide students with such valid acoustic models of the phonemes of the L2.

\section{A NEW METHOD OF TEACHING THAI PRONUNCIATION TO L2 BEGINNING LEARNERS OF THAI}

\section{The Thai Tonal System}

There are five tones in Thai (figure 2). There are 5 distinctive tones (pitches) in Standard Thai. They are: (1) mid level tone (here represented with the number 1), for example: khaal (to be lodged in); (2) low level tone (represented with the number 2), for example: khaa2 (Galanga, an aromatic root);(3) falling tone (represented with the number 3), for example: khaa3 (I, slave, servant);(4) high level tone (represented with the number 4), for example: khaa4 (to sell); (5) rising tone (represented with the number 5), for example: khaa5 (leg). The following chart shows the contour pattern of the 5 tones.

\section{Figure 2. Contour pattern of the 5 Thai tones}

\section{Insert figure 2 here:=03_zhang_figure2.tiff}

The design of the SEA method has also drawn from research findings on (i) how very young infants use prosodic packaging of clausal units to facilitate their memory for speech information (Hirsh-Pasek et al., 1987; Mandel, Jusczyk, \& Kemler Nelson, 1994); (ii) formulaic sequences in foreign language learning improves the fluency of L2 learners' foreign language production (Wood, 2009) (iii) a speaker's natural synchronization of speech and movements (Condon, 1971; Condon \& Ogston, 1967); (iv) how rhythmicity is used as source of prediction in caring situations between babies and carers (Maier, 2004) and, (v) therapeutic uses of movements for speech and hearing impaired children (Brüll, 2003; DiJohnson \& Craig, 1971); (vi) Learning through multi-modalities is more effective for pronunciation training than a single modality 
(Derwing, Munro, \& Wiebe, 1998). For a comprehensive literature review, please consult Zhang (2006).

The question might arise as to whether this method is similar to the Total Physical Response (TPR) (Asher, 1977) method developed by Professor James Asher in 1977. SEA is not like TPR because:

1. It does not adopt the strategy of delayed speech in the arrangement of learning activities and materials. In fact, students are required to produce almost immediately.

2. It acknowledges the differences between learning of L1 and the acquisition of a second language in that it promotes the motivational energy engendered by adult students' social needs to communicate.

3. It does not organize teaching materials and activities on some arbitrary principle of difficulty or developmental sequence. The materials were chosen first and foremost according to communicative principles and relevance to the students.

4. Apart from teaching the language, students were also taught a number of processing load lightening skills so that they learnt how to physically, not just mentally, produce the language in its optimal prosodic contexts. The physical gestures for tones also equip them with physical reminders that tone is an indispensable part of Thai pronunciation. In other words, the approach does not work on one isolated aspect or element of Thai. It works simultaneously on segmental, suprasegmental, grammatical and syntactic systems.

5. Most importantly SEA does not use gesture as a mnemonic devise for enhancing the acquisition of vocabulary items only. It acts as a reminder of a whole set of known and unknown memory traces. SEA may also use movement and prosody to help students to segment the language stream.

Asher's approach to language learning, however, assumes that listening should be developed before speaking because this is what happens when a child learns his/her L1 and delaying speech seems to reduce stress(Gary, 1975). In adults who are learning Thai as a L2, the proposed constructs of phonological store and articulatory rehearsal (Gathercole \& Baddeley, 1993) might already be fully functioning in their L1. Theoretically, even if we want to delay production in L2, the developed coordination in the phonological store and the articulatory rehearsal might not be able to be stopped. Secondly, as language learning theories have convincingly argued, the need to keep the language learning process communicative for social reasons, it is both theoretically unsound and potentially de-motivating if adult learners are prevented from trying out the newly learned language through oral communication.

In terms of classroom activities, Richards and Rodgers (1986) stated that the labeling and ordering of classroom activities in TPR seem to build on the structural view of language in that the mastery of a language is through the sequential mastery of phonemes, grammatical units, lexical items and grammatical operations. One key objective of TPR is the use of action-based drills in the imperative form. It is difficult to see how these commands are linked to the L2 as a whole apart from being an element of it. SEA, on the other hand, does not order classroom activities according to structural views. It is based on the communicative needs of students. Thai also has a very complicated stress system with the duration of syllables as one of the most prominent features used to distinguish stressed and unstressed syllables in Thai (Hiranburana, 1971, Luangthongkum, 1977). There is also interplay between tone and intonation which results in four intonation contours or Tunes being postulated (Luksaneeyanawin, 1998). A full and comprehensive description of the Thai language might be of interest to phoneticians or linguists. It would be impossible for any language teacher of Thai to explain the complex system of Thai 
to L2 students. In normal everyday use, utterances in Thai are spoken with all the characteristics of Thai (tones, stress, intonation, rhythm, vowel lengths and so on) combined. Therefore, as we intend to teach our L2 students to be comprehensible to native speakers of Thai in real life, activities should focus on phrases or sentences rather than individual words or lexical tones. This is particularly important when teaching L2 students from other tonal languages such as Mandarin and Vietnamese as the likelihood of Mandarin and Vietnamese tones interfering with the perception and production of Thai tones is great. Furthermore, since lexical tones change their character when in the environment of other words, a mastery of individual lexical tones is no guarantee for success in speaking conversational Thai. Figure 3 is a schematic outline of SEA, showing the two principle phases and their sequencing.

Figure 3. Schematic outline of SEA, showing the two principal phases and their sequencing

\section{Insert figure 3 here:=03_zhang_figure3.tif}

Recent research in neuroscience has also offered evidence that: (i) adult human auditory brainstem is capable of being changed following short-term linguistics training such as tone differentiation (Song, Skoe, Wong, \& Kraus, 2008); (ii) English speaking learners with previous musical training could use pitch contrasts to identify words and could understand different speakers speaking the pitch contrasts. However, English speaking learners who do not have previous musical or speech (tone) related training, achieved better pitch contrasts identification if only one speaker is used in speaking the pitch contrasts (Lee, Perrachione, Dees, \& Wong, 2007). These findings from research cited above lend support to a range of instructional strategies involved in the learning sequence of SEA in teaching Thai. For instance, in order to cater for less experience learners, in the teaching of experimental group students, a single native speaker was used to teach the class. The learning sequence of SEA is described in the next section.

\section{Phase 1: The Sensitization Phase}

The activities in Phase 1 Language sensitization process were concerned with focusing on the rhythm and intonation of the language not on lexical tones. All linguistic items were presented in their situational contexts so that students were engaged in meaningful and useful language practice. The smallest unit of the language being presented is a sentence rather than individual words or compound words.

The first step in the sensitization session is to ask students to lie on their backs on the floor and if possible, with the classroom darkened, then carry out mind-calming exercises for some five to ten minutes. This allows them to be more relaxed and more receptive to the language input. The teacher first gives this instruction to the class:

"Now, leave your seat and lie comfortably on the floor and listen". Then the following audio file is played or read out in English:

Imagine that you are lying on your back on the grass on a warm summer day, and that you are watching the clear blue sky without a single cloud in it (pause). You are lying very comfortably, you are very relaxed and happy (pause). You are simply enjoying the experience of watching the clear, beautiful blue sky (pause). As you are lying there, completely relaxed, enjoying yourself (pause), far off on the horizon you notice a tiny white cloud (pause). You are fascinated by the simple beauty of the small white cloud against the clear blue sky (pause). The 
little white cloud starts to move slowly toward you (pause). You are lying there, completely relaxed, very much at peace with yourself, watching the little white cloud drift slowly toward you (pause). The little white cloud drifts slowly toward you (pause). You are enjoying the beauty of the clear blue sky and the little white cloud (pause). Finally the little white cloud comes to a stop overhead (pause). Completely relaxed, you are enjoying this beautiful scene (pause). You are very relaxed, very much at peace with yourself, and simply enjoying the beauty of the little white cloud in the blue sky (pause). Now become the little white cloud. Project yourself into it (pause). You are the little white cloud, completely diffused, puffy, relaxed, very much at peace with yourself (pause). Now you are completely relaxed, your mind is completely calm (pause), you are pleasantly relaxed, ready to proceed with the lesson (pause) (Bancroft, 1978, p. 178).

This constitutes the relaxation phase of the classroom procedure. As Lian noted (Lian, 1980 ): Relaxation of the body will bring about a lowering of conscious and unconscious resistance to the learning of a FL. Speech and the production of sounds appear to be the result of the muscular behaviour of the body as a whole which, with appropriate reinforcement, has given rise to a number of set patterns of muscular contractions. If these still operate when one attempts to learn the articulatory patterns of a FL, then the resulting articulatory sequences will be deformed, sometimes beyond recognition.

It becomes very important to reduce the influence of the set of individual muscular tensions and movement to a minimum when learning Thai. Relaxation techniques appear to be an effective way of reducing, if not eliminating, such conditioning so that it can be replaced with another set of muscular tensions and movements: those of Thai. For this reason, the relaxation phase of the course is extremely important. Relaxation is therefore the first step recommended for the teaching of Thai.

Step 2: Students and the teacher walk around in circles and hum along to the rhythm of the sentences without vowels and consonants (5 times). This is used to highlight the intonation and rhythm of Thai. It is imperative that in this step, the teacher does not start by modeling or reciting the target sentence with consonants and vowels intact as any such modeling defeats the purpose of focusing on the melody of the sentence without the interference of consonants and vowels.

As the input and output of the language uttered mutually reinforce each other, three factors must be considered in order to maximize the benefit of production and perception. First, such a structure should be relatively easy to produce a maximum of 5 to 7 syllables. Second, humming allows L2 students develop a much better perception of the melodic patterns concerned. This delayed exposure to consonants and vowels shifts students' attention to other often neglected aspects of the language such as rhythm and intonation. It is also to encourage the creation of mystery so that students' curiosity is aroused.

Step 3: The teacher claps to the rhythm and the beat of the language and then ask students to follow. The students, while listening to and "feeling" the intonation patterns, begin to move in harmony with the rhythm and intonation of the sentences modeled by the teacher. The teacher provides the beat and the rhythm of the sentences according to the stress and discourse features of the sentences. The clapping to the intonation patterns created a rhythm that students could 
follow while walking in a circle. This allows students to experience the rhythm of the sentence and observe different groupings of the words in a sentence. This also enables them to observe the key words in a sentence and realize that not all words are of equal value and that in making oneself understood, one needs to get the key words right to be understood.

Step 4: The teacher walk about with feet coming down on every syllable, to get the body used to producing a tone such as the tense downward tone that is also loud (the falling tone) ( $3^{\text {rd }}$ tone). The teacher also raises or stretches upwards as though attempting to touch the ceiling. This allows students to experience the tenseness of the body in producing the rising tone ( $5^{\text {th }}$ tone). Students are then instructed to perform the same gestures. Students are also instructed to adopt a forward lumping of the shoulders for $1^{\text {st }}$ and $2^{\text {nd }}$ tones in Thai as the production of these tones need a relaxed posture. When the teacher detects that after the humming and clapping, students still fail to perceive the rhythm and melody of the sentences correctly, gesturing provides students further ways of manipulating the body tension to achieve certain rhythmic structures. Step 5: Mouthing the words: In this step, the teacher instructs students by saying "Continuing with the movements, now mouth the sentences while I say them out loud" (Step 5). For the first time in the learning sequence, so far, students are hearing an intelligible sentence. They are asked not to say anything but merely to mouth the words. Mouthing the words gives students the opportunity to practice the articulation of the sounds of the words without, in fact, placing them on an intonational background actually produced themselves. This technique should lead to a reduction in the number of articulation errors.

Step 6-7: Adding words to the intonation patterns: The teacher then says "Now repeat after me, and then add words to the intonation." This again is done for five times (Step 6). The teacher then instructs everybody to repeat the sentence in chorus while constantly checking that each student is reproducing the sentence correctly (Step 7).

Steps 2-5 isolate each element of articulation e.g. humming, clapping, gesturing and mouthing before restoring them to a normal context in steps 6-7. This procedure has the further advantage of eliminating as many difficulties as possible in terms of comprehension of the sentence. Consequently, by the time students are actually asked to repeat a full sentence, they will have practiced each of its constituent elements many times. They will look forward to achieving success in the next step of the process which should present little additional difficulty.

Repetition first takes the forms of chorus work and then individual repetition. Chorus work provides an environment where anxiety about speaking an L2 could be reduced to a minimum. Although carrying out chorus work in class is "safe", it is hardly ever likely to be encountered in real life. It is important, , that students also be conditioned to speak with self-assurance in the normal communication situation. To this end, at the appropriate juncture such as at the end of a conversation, a ping pong game could be played with the newly acquired TL. For instance, after practicing the following conversation:

\section{Conversation 1 (บทสนทนาที่ ๑) Greetings for people who first meet} สวัสดีค่ะ ดิฉันชื่อสุภา คุณชื่ออะไรคะ

สุภา : Hello, my name is Supha

$$
\text { สวัสดีครับ ผมชื่อศักดา ยินดีที่ได้รู้จักครับ }
$$

ศักดา : Hello, my name is Sakda. It's very nice to meet you.

สุภา : ยินดีที่ได้รู้จักเช่นกันค่ะ

It's also very nice to meet you. 
in the ping pong game, a ball made out of a piece of used paper, is thrown around the group while the group is still in a circular formation. The person holding the ping pong ball plays the role of Person A. He/she then throws the ball to another student who plays the role of B after saying, for example, สวัสดีค่ะ ดิฉันชื่อสุภา คุณชื่ออะไรคะ (Hello, my name is Supha. What is your name?) When B catches the ball, he/she needs to answer the question asked with the appropriate answer. In this case, สวัสดีครับ ผมชื่อศักดา ยินดีที่ได้รู้จักครับ (Hello, my name is Sakda. It's very nice to meet you). B throws the ball to another student by assuming the role of Person A and asks the question 'สวัสดีค่ะ ดิฉันชื่อสุภา คุณชื่ออะไรคะ (Hello, my name is Supha. What is your name?). This goes on until all members of the class have been involved in the conversation. This game should be played after learning every two sentences in the above conversation.

Experience testifies that as the students' confidence grow, so will their willingness to participate in this activity (Lian, 1980; Zhang, 2006). Though the group situation could not be totally under a student's control, to some extent, it is possible for students to work at their own pace within the group situation because each time they listen and observe another student's production of the utterance, their own learning is being reinforced. Through the ping pong game, students get the opportunities to listen to his/her classmates using the learned sentences to communicate thus revising the newly learned language in his/her own head. The randomness of the game also creates a bit of tension which encourages the students to rehearse the language silently while observing other students' performances. For the teacher, if a common error occurs, this game gives her/him an opportunity to correct the error using gestures and rhythm.

Repetition exercises such as this provide reinforcement at both the perceptual and articulatory levels. By the time the students complete an "average" sensitization session, they would have repeated or been exposed to the same pattern or a set of closely related patterns in their situated context about 35-40 times. Such a high number of repetitions are, of course, a great reinforcer of perceptual and articulatory skills.

Throughout the learning sequence, translation and writing down the sentences are not needed until the last moment. By the time students come to write down the meaning, they will have already internalized and memorized the melody of the sentences. The activities in the sensitization phase offer students a range of physical ways for remembering the Thai sentences learned beyond the set contact hours each week. These measures set up a series of learning steps and establish a common metalanguage between students and the teacher that can be used for selfmonitoring in self-access learning at home.

\section{Phase 2: The Language Consolidation Phase}

After four weeks, students would have covered all the language required to discuss their own family. It is at this juncture that a genuinely communicative activity is introduced in order to further consolidate the language learned. This communicative game is called a family tree game. According to Gatbonton and Segalowitz (2005) 'an activity is genuinely communicative if it involves at least two participants working together to complete a task by exchanging information possessed by one and not the other'(p. 331). Two requirements for genuineness of communication are implied in this definition. First, new information must pass from one interlocutor to the other (an 'info gap' is filled), and the solicited information must be crucial for the continuation of the assigned task (the information sought and passed on must genuinely be needed for later communication). 
In the 'Family' game, first the students are asked to write a piece of paper that contain information about their immediate family in the first week by answering questions like 'How many members are in your family?', 'How many brothers and sisters do you have?', 'Who are they?', 'How old are they?' and 'What are their names?'. Then the teacher creates a 'Find someone who' sheet using the information from the students in the class. Information on the 'Find someone who' sheet could be 'Find fellow student(s) who have two younger brothers and one younger brother.' Then in the fourth week, each students will be given a 'Find someone who' sheet which contains information about the 22 students and an individual character sheet which contains only information for that particular character. Each student's job is to ask these target questions: 'How many members are in your family?', 'How many brothers and sisters do you have?', 'Who are they?', 'How old are they?' and 'What are their names?', in order to find all the students listed on the 'Find someone who' sheet. Students are instructed not to stop until all students have been found. In the completion of this game, students have to move around the class posing the required questions thus practicing the same set of questions over and over again. Like the steps in the 'Sensitization phase', the activities in the 'Language consolidation phase' are inherently repetitive. After completing this game as a spoken activity, students are instructed to work in pairs to construct a family tree by asking each other the same set of questions. Here, too, repetition is necessary to gather the information needed to complete the task. From a psychological perspective, because of the high consistency of situation-utterance correspondences across the repeated events, this repetition will lead to automaticity in both reception and production (Schneider \& Chein, 2003 cited in Gatbonton, Segalowitz (2005) ).

\section{Content of Teaching}

In this course, because all students were zero beginners of Thai, the language input chosen was phrases and sentences involved in common pragmatic situations such as introduction, talking about one's family and so on. The smallest unit was a sentence rather than a word or phoneme though a vocabulary list was also provided. The following is an example of the teaching material used in the course. Notice each sentence and vocabulary is attached to its own sound file. When clicked, the sound file is retrieved by Sptool and opens up in a different window in which the pitch curve of the sentence is shown. The course data CD-ROM also contains teaching materials in html format; all associated sound files and the speech tool (Sptool). An audio CD-ROM of the sound files is also provided with the course materials.

\section{Conversation 1 (บทสนทนาที่ ه) Greetings for people who first meet}

สวัสดีค่ะ ดิฉันชื่อสุภา คุณชื่ออะไรคะ Hello, my name is Supha。What is your name?

สุภา : สวัสดีครับ ผมชื่อศักดา ยินดีที่ได้รู้จักครับ

ศักดา : Hello, my name is Sakda. It's very nice to meet you. ยินดีที่ได้รู้จักเช่นกันค่ะ

สุภา :

It's also very nice to meet you.

\section{Conversation 1 Vocabulary (คำศัพท์ในบทสนทนาที่ ๑)}

สวัสดี Hello or goodbye 
ค่อ

ดิฉัน

ชื่อ

คุณ

อะไร

คะ

ครับ

ผม

ยินดีที่ได้รู้จัก

ยินดีที่ได้รู้จักเช่นกัน
Polite particle for females

I, me (female speaker)

Name

You, a second person pronoun used as a polite way to call others, normally precedes the name of a person

What?

Polite particle used by female speaker at the end of a question

Polite Particle for male speaker, used at the end of the sentence and as "yes"

I, me (male speaker)

Nice to meet you.

Nice to meet you too.

In SEA, the goal of teaching is to help students learn to use whole utterances flawlessly, effortlessly and appropriately. To achieve this aim, an environment with a low affective filter needs to be created. Similarly, due to the tonal nature of the Thai language, it is especially important to sensitise L2 learners to the tonal nature of Thai particularly for L2 students who come from other tonal language cultures because of the necessity to lessen the impact of tones in L2 students' mother tongue. For these reasons, utterances are taught kinaesthetically, visually and physically to highlight the tonal nature of Thai language. Through these steps students learn to see, move and feel the language. Analysis of these constructions is intended only to facilitate automatizing the whole utterance.

Given the complexity of the various processes involved in perception and phonation, learning processes in this domain is most likely to be operating at the unconscious level. An intellectualization of these processes, such as comparing the phonetic systems of Thai and Chinese and English is likely to interfere with students' perception as it activates the 'mothertongue sieve' in the task of learning Thai and thus interferes with learners' perception of Thai sounds and prosody. In SEA, the traditional cognitive load lightening measure such as translation into Chinese or English, or writing in the standardized romanization system of Thai with tone diacritics were deliberately and intentionally not used at all in teaching Thai in the study under discussion. Similarly, in the teaching of English to speakers of other languages, Fraser (2001) also advocates not using IPA symbols with beginners because "it can detract from the real issue, which is pronunciation, and because the concept of 'phoneme' is quite an advanced one for many ESL learners)."

Through every aspect of this approach, it was thus intended that the language learned is constantly associated with a stimulating and pleasurable emotional environment. Such environment ensured that what was learned becomes deeply embedded. Through these steps, by observing the teacher's native speaker (NS) behaviour, and by perceiving the differences 
between their own and the teacher's behaviour in producing Thai, learners were able to respond to teacher feedback readily. These pedagogic measures also were designed to instill in students certain memory traces by physically 'marking' on their brains so that these memory traces could be reactivated once feedback either from the Sptool or from any other sources has been received. These memory traces were essential in enabling students to automatize sentences learned and act upon the feedback received.

The experience of teaching Mandarin testifies that students became more sensitive to the importance of grammar after they successfully completed the audition process (Zhang, 2006) . Having automatic access to the formulaic constructions made the students more receptive to the grammar learned. Furthermore, in a Mandarin classroom in which the L2 learners were all English speakers from Australia who had virtually no grammatical knowledge of English, too much grammar in such a course would have added cognitive load on the students (Zhang, 2006). This was the reason why grammar explanation was hardly used in this study.

\section{Role of the Teacher}

In SEA, the teacher plays the role of what Morley (1991) describes as one of 'speech coach or pronunciation coach' (p.507). Instead of just correcting L2 learners' mistakes, the 'speech coach' 'supplies information, gives models from time to time, offers cues, suggestions and constructive feedback about performance, sets high standards, provides a wide variety of practice opportunities, and overall supports and encourages the learner' (Morley, 1991, p. 507).

In SEA, for the best possible results, a teacher should supervise at least the sensitization session. It is in this session that he/she would ensure that the prosodic structures have been perceived correctly. If incorrect perception of the prosodic structures has been detected, he/she should take immediate corrective action. Moreover, he/she should also ensure that students are developing the necessary "feel" for the language and self-synchrony (refer to Step 4: Incorporation of movement and gesture).

It is essential that the teacher should constantly monitor all the students' performances. It has been argued that a teacher working under such conditions would be incapable of picking out the errors committed by students, because he/she cannot listen to all of them individually.

Experience in this course indicates that in the majority of cases only one or two persons in a group would be significantly "out of tune" with the rest of the group. Such persons are easily identified and corrected immediately. In this way, students would not spend a considerable time reinforcing their errors during "private" repetitions as they would likely to do in a language laboratory. The teacher is also in a position to determine whether generalized errors are occurring and to correct them in a variety of ways e.g. by exaggerating the model sentences at the point of difficulty or by using corrective gestures.

In order to reduce the gap between real communication and exercises of this nature, the teacher should attempt to establish the kind of situations in which the sentences might be uttered e.g. asking students to maintain eye contact (rather than closing one's eyes in an attempt to recall words) when speaking to each other. He/she should also remind students of the importance of gesture in the communicative act and should demonstrate this by taking part in the activities of the group.

The teaching techniques described in Steps 1-8 teach more than the few phrases chosen each week. In teaching the rhythm, and the eurhythmic gestures, we are also imparting onto the students how Thai speakers synchronize with each other in speech, in proximity and in body 
language. In the course under study, students were strongly encouraged to form conversation exchange groups with NSs in the community so that they could put into practice the prosodic patterns they had been learning. This was the privileged place for the actualization of prosodic patterns and for hypothesis testing with real NSs of the TL accompanied with the realities of communication.

\section{Teaching Learners How to Learn}

The weekly routines in the sensitization and consolidation phases of SEA also establish a shared meta-language between the teacher and the students. He/she should also inform students that though the teaching method is fun, they would still be required to do a significant amount of work. This meta-language is the result of the teacher's implies that the teacher should, ideally, possess some knowledge of articulatory phonetics and kinesics and his/her ability to diagnose errors in tones, intonation and in synchrony. In the case of Thai, language correction should move away from the traditional verbal correction such as "no, it's a third tone, not a first tone" to include provision of feedback through movement and gesture in the appropriate prosodic contexts. Last but not least, the teacher needs to develop the ability to sit back and encourage students to produce the language, i.e. increasing student talk rather than teacher talk. In summary, the relaxation exercise, humming, body movement and gestures, mouthing the words and then repetition offer students a range of physical ways for recalling and correct their own tones. These measures set up multiple corrective feedback mechanisms that can be used for self-access learning at home.

\section{The Role of the Speech Processing Tool and Course Data CD-ROM}

Developing a feel for the TL, no matter how well designed the learning environment is, takes time. While student can get feedback from their language teachers during class, in private study this kind of on the spot feedback is usually absent. In this course, students in the EG were learning Thai in Thailand (a second language rather than a foreign language situation) thus their opportunities to test their Thai and to get feedback from Thai native speakers increased. However, in order to reduce L2 students of Thai's anxiety when trying out the Thai language they learned on their Thai native speaking friends, an audiovisual feedback tool (Sptool) was provided to allow the comparison of a student's Thai language production with that of a native speaker's Thai language.

There are already many Computer Assisted Pronunciation Technology (CAPT) systems in the market place which provide instantaneous feedback in the form of spectrograms and waveforms. However, according to Neri, Cucchiarini and Strik (2002), two main reasons make these CAPT systems ineffective. First of all, the simultaneous display of the incoming learner's utterance and the model utterance wrongly suggests that the student should ultimately aim at producing an utterance whose acoustic representation closely corresponds to that of the model. In fact, even though two utterances have very different waveforms, they may both be very well pronounced according to a native speaker. Secondly, these kinds of displays are not easily interpreted by students, because they provide too much information on the student speech's amplitude, pitch, duration which inhibits the learners from being able to pick up the most salient aspects of the acoustic signal. Furthermore, CAPT systems such as Praat (Boersma \& Weenink, 2003) are too specialized for student use, if they are not highly computer literate. 
Bearing in mind that the feedback provided has to be interpretable and easy-to-use for students, the design of the Sptool is to measure the pitch curves of sentences of languages only. This means the Sptool is capable of showing the pitch curves as well as length and loudness (correlates of Thai) of utterances in Thai speech through the display of the height and length of the words within utterances. The height and length of the curves also correspond to the articulatory gestures needed to produce rhythmic structure of sentences used in the sensitization phase. Combined with the articulatory gestures it is hypothesized that this will make the feedback long lasting.

In this study, all the written teaching materials on the data CD-ROM were linked to sound files and passed through the Sptool. Once passed through the Sptool, the learner could listen to the teacher's model pronunciation by clicking on the 'teacher' icon. With one click, he/she could hear the model sentence and see the pitch curve of the model sentence displayed on the screen. If the learner wanted to hear a smaller chunk of the sentence, then he/she could select the bit of the curve by dragging the cursor over the portion he/she wanted to hear. After listening to the sentence numerous times, the learner could decide whether he/she wanted to record his/her own production.

Some of the activities in the lecture sequence could be duplicated in different forms through the use of the Sptool. While the classroom sequence was more or less teacher driven and physical, the Sptool allowed the lecture sequence to be experienced differently. In the following sample sentence from figure 4, 'dilchan4 chUU3...' (I am .....)

Figure 4. Picture of the Sptool showing the sample sentence: I am .... (dil chan4 chUU3...?)

\section{Insert figure4 here: $=03$ _zhang_figure4.tif}

'di1 chan4 chUU3...?' is a key string of words and the curve clearly shows that the 'chUU3' is clearly longer than the rest. This information was extremely important when training students to accept that the ultimate aim of producing an utterance which was acceptable by native speakers was NOT to produce an utterance whose acoustic representation was an exact match or even closely corresponds to that of the model. It was vital to impress upon the students that the importance in producing a comprehensible sentence in Thai is to be able to produce the key parts of the utterance correctly.

The use of the Sptool encourages students to reflect on and explore in the process of learning. Furthermore, being able to experience each sentence repeatedly through the Sptool creates an environment in which students can totally immerse themselves consciously and unconsciously in the language. As the Sptool was used to interpret the sound files on the CD-ROM, students would encounter a variety of language which was necessary for learners to continue to learn and improve (Egbert, Chao, \& Hanson-Smith, 1999). The pitch curves on Sptool also allowed students' output to be compared to the original input thus affording instant feedback. This reduced L2 students' anxiety in speaking the target language (TL). The similarity of the native speaker and the L2 student's pitch curves also served as goals for intelligibility and accuracy thus allowing L2 students to judge whether they made progress. This ability to test their own hypotheses about L2 sounds was also conducive to the development of self awareness in learners. As the practice activities were all situated in personalized and real life contexts, tasks that learners were asked to complete were authentic thus enabling L2 learners to practice interacting with an authentic audience in the safety of their own home (Egbert, Chao, \& Hanson-Smith, 1999)(Egbert et al., 1999). Furthermore, because L2 students had been taught how to use their 
body to experience the language, their body acted as another source of feedback thus giving learners learning autonomy (Egbert et al., 1999).

\section{THE STUDY}

\section{Subjects in the Study}

There were two groups of students in the study: an experimental group (EG) and a control group (CG). EG consisted of 24(12 pairs) international students who enrolled in the Thai Language for Foreigners course at KhonKaen University, Thailand. They had four hours of face to face contact per week over six weeks (a total of 24 hours). They were taught by SEA for 32 hours and used data and audio CD-ROMs which included a speech processing tool (Sptool). The students in CG were 22 (11 pairs) Chinese students who studied Thai language at Guangxi University for Nationalities, China. These students in CG speak Mandarin Chinese as their first language. The CG students were taught by a Thai teacher using traditional method with the same textbook and did not have any ICT support. However they studied Thai for 44 hours over 11 weeks with 4 face to face contact hours per week.

By the end of the experiment, data from EG was compared with data from CG using the same oral and written testing mechanisms. A set up using Sony microphone plugged into a Dell laptop computer using Cooledit 2000 (Syntrillium, 2002) was used to make the recording. In the next section, the results the project will be reported.

\section{RESULTS}

\section{Research Questions}

1. "What are the effects of SEA on L2 student oral performances in learning Thai as a foreign/second language?"

2. How did the students in the experimental group use Sptool to aid their learning of Thai?

\section{Method}

The effects of SEA on L2 student oral performances were measured by comparing CG and EG's end of course oral performance data, in terms of the quantity and quality of the Thai language produced. Sound files from both CG and EG were also subjected to independent marking by 12 Thai native speaker markers from the Faculty of Humanities and Social Sciences, KhonKaen University. The researchers were not among the native speaking markers. This was called the 'perceptual test'. All markers participated in the current perceptual test on a voluntary basis. Materials marked were spoken conversations from both the CG and EG (11 and 12 pairs respectively) of students. The markers did not know which group each student belonged to at the time of marking. The number of samples marked was 23.

Statistical analyses were performed using the Analysis Toolpak in the Excel package and SPSS statistical package. The critical significance level was set at $\mathrm{p}<0.05$ throughout the study. All oral production data from the 23 pairs of subjects (both CG and EG) were analysed. A 2 tail T-Test for two samples of unequal variance were used to analyse the various characteristics of the conversations spoken by all the subjects involved in this study. 
To triangulate the results from oral performances and the perceptual test, an open-ended questionnaire was also distributed to students to gauge their patterns of use of Sptool. Students in EG were also asked to keep a diary on the use of Sptool throughout the learning period.

\section{Results of the Perceptual Test}

Results of this perceptual test (seen in figure 5) by native speakers confirm that the students taught by SEA from EG performed better than the students in CG who were not taught by SEA. Students in EG achieved an average rating of 21.79 out of 25 with a standard deviation of 1.6 compared to the CG's average rating of 20.95 out of 25 with a standard deviation of 1.13 . The difference in the means of the perceptual rating scores given by the markers was statistically significant at $\mathrm{p}<0.05$ level $(\mathrm{p}=0.03)$. This means EG students performed significantly better than the students in CG. Furthermore, the level of agreement reached by the 12 native speakers was very high as indicated by an inter-rater reliability score of 0.903 (Cronbach alpha).

Figure 5. Ratings of student oral performances in CG and EG by independent raters in 2010

\section{Insert figure5 here:=03_zhang_figure5.tif}

\section{Quality of the Conversations}

The quality of the conversations produced by both groups was also measured by the average number of words produced per person (shown in figure 6). In the CG $(n=22)$, students produced an average of 67 words with per person whereas students' in EG $(n=24)$ produced an average of 158 words per person.

Figure 6. Number of words produced by students in $C G$ and EG

\section{Insert figure 6 here:=03_zhang_figure6.tif}

However, students in CG produced many more fillers such as 'ums' and 'ahs' than students in EG. On average, students in CG produced 93fillers and students in EG produced 48 fillers. The positions of the fillers are also interesting. The fillers were analysed according to the position of their occurrences. Fillers could occur in the following ten positions:

$1=$ between subject and verb

$2=$ at the end of a sentence

$3=$ between noun and an adjective

$4=$ between verb and object

$5=$ before prepositional phrase

$6=$ at the beginning of a sentence

$7=$ between verb and adverb

$8=$ before conjunction

$9=$ at the beginning of a phrase

$10=$ at the beginning of words (between words)

Table 1. Distribution of fillers in ten different positions produced by the 12 pairs of students in CG 


\begin{tabular}{|l|l|l|l|l|l|l|l|l|l|l|l|l|}
\hline Positions & 1 & 2 & 3 & 4 & 5 & $\mathbf{6}$ & 7 & 8 & $\mathbf{9}$ & $\mathbf{1 0}$ & lol & Total words \\
\hline $\begin{array}{l}\text { Total no. of fillers } \\
\text { in different } \\
\text { positions }\end{array}$ & 1 & 2 & 0 & 0 & 2 & $\mathbf{4 7}$ & 0 & 1 & $\mathbf{2 4}$ & $\mathbf{1 7}$ & $\mathbf{1 5}$ & $\mathbf{1 6 0 0}$ \\
\hline $\begin{array}{l}\text { Average no. of } \\
\text { fillers }\end{array}$ & $\begin{array}{l}0.04 \\
2\end{array}$ & $\begin{array}{l}0.08 \\
3\end{array}$ & 0 & 0 & 0.08 & $\mathbf{1 . 9 6}$ & 0 & 0.04 & $\mathbf{1}$ & $\begin{array}{l}\mathbf{0 . 7 0} \\
\mathbf{8}\end{array}$ & $\begin{array}{l}\mathbf{0 . 6 2} \\
\mathbf{5}\end{array}$ & $\mathbf{6 7} \mathbf{p p}$ \\
\hline
\end{tabular}

Key: lol: laughing

Pos.= position number

$1=$ between subject and verb

$2=$ at the end of a sentence

$3=$ between noun and an adjective

$4=$ between verb and object

$5=$ before prepositional phrase

$6=$ at the beginning of a sentence

$7=$ between verb and adverb

$8=$ before conjunction

$9=$ at the beginning of a phrase

$10=$ at the beginning of words (between words)

Table 2. Distribution of fillers in different positions produced by the 12 pairs of students in EG

\begin{tabular}{|l|l|l|l|l|l|l|l|l|l|l|l|l|}
\hline Positions & 1 & 2 & 3 & 4 & 5 & 6 & 7 & 8 & 9 & 10 & lol & $\begin{array}{l}\text { Total } \\
\text { words }\end{array}$ \\
\hline $\begin{array}{l}\text { Total no. } \\
\text { of fillers in } \\
\text { different } \\
\text { positions }\end{array}$ & 5 & 1 & 0 & 1 & 0 & 29 & 0 & 1 & 11 & 0 & 3 & 3790 \\
\hline average & 0.2 & 0.042 & & 0.042 & 0 & 1.21 & 0 & 0.042 & 0.46 & 0 & 0.12 & $158 \mathrm{pp}$ \\
\hline
\end{tabular}

Key:

$1=$ between subject and verb

$2=$ at the end of a sentence

$3=$ between noun and an adjective

$4=$ between verb and object

$5=$ before prepositional phrase

$6=$ at the beginning of a sentence

$7=$ between verb and adverb

$8=$ before conjunction

$9=$ at the beginning of a phrase

$10=$ at the beginning of words (between words)

It can be seen that students in CG used many fillers in positions 6, 9 and 10 in their conversations (see Table 1) whereas students in EG used far fewer fillers and used fillers mainly at the beginning of a sentence (position 6) or phrase (position 9) but none at position 10 (see Table 2). Some fillers were also used in between the subjects and the verbs by students in EG. In the data collected from CG, students used a lot of laughter as fillers too.

In fluency research, speed and effortlessness seem to be the two main characteristics of a fluent performance (Chambers, 1997) . Of course because the students tested in this project are only beginning students, the definition of fluency, is defined as 'The maximally effective operation of the language system so far acquired by the students (Brumfit, 1984, p. 57).

The results in Table 2 suggest that students in the EG had better recall of vocabulary and phrases, i.e. more fluent, as demonstrated by making no fillers within words (at position 10), less use of 
fillers in position 6,9 (almost half as many fillers in total) and producing almost twice as many words in total.

\section{Qualitative Data}

At the end of the course, students taught with SEA, were asked to fill in an open-ended questionnaire to gauge their attitudes towards the use of Sptool and the CD-Rom. From 20 questionnaires collected at the end of the semester, 17 students felt that Sptool was useful in their learning and most of them used the computer materials and Sptool for at least 7.5 hours per week per person. This is a significant amount of time spent on the task of learning Thai especially when compared to other similar courses which used SEA to teach foreign languages (maximum 3 hours per week per person) (Zhang, 2006).

As one student wrote in the open-ended questionnaire:

Learning the language is difficult. But with the help from teachers and the CD, we could learn something that we have not been thinking of. Sptool and the files on CD helped a lot. I would definitely say that it [Sptool] is very useful because it checks out pitch and tone when I speak the language. I would like to say Sptool can be used to learn other languages as it monitors and tracks your pitch.

Throughout the course, participating students in EG were also asked to keep diaries on the using of Sptool for learning Thai in English (their second language). Students were overwhelmingly positive towards Sptool. While some students persisted with Sptool, some found it too difficult to use and preferred to learn from their Thai friends. Most treated Sptool as a teacher and also checked their pronunciation with their Thai friends.

One student also used humming (which was demonstrated during the sensitization phase) in her private study:

I think num-sa-korn is hard, so I use Sptool to listen to the pronunciation more than 3 times and watch the tone, then I use the way of hmming (sic) to practice the tone and practice to pronounce..... I record my pronunciation and compare, it's similar. So I read 2 times for remember the word.

For long words, this student also invented her own strategy:

The reason that I can't remember those words is they are too long, and they are difficult to pronounce. So I use Sptool to separate every word's tone, and pronounce part by part, and then make up them. At the beginning, my pronunciation is too strong in the end of every part, so when I make up a word, it sounds like strange, so I use hmming (sic) to practice. Finally, I got it....it's close to original one around $80 \%$.

It can be seen from the diary entry quoted above that for this student, Sptool was playing a role of the teacher in her private study because instead of trying to remember how a phrase was pronounced in the sensitization phase, she checked the phrase using Sptool first, then practiced how to use her body to hum the phrase, practice it, then check against Sptool. Only when the pitch curves were similar, she tried to memorise the word. In other words, in her private study, she managed to transfer the strategies she was taught in the face-to-face session to her private study. Similarly, the second quote demonstrated how she broke a phrase up into its constituent parts tone by tone and then restored all the parts into back into the target phrase. This technique 
was demonstrated and practiced weekly in the sensitization phase thus enabling this student to adopt the same strategy in her own learning.

Some EG students' diary entries, however, seemed to suggest that L2 students needed to be trained longer in using Sptool. This was particularly evident from male students' diary entries. As the sample sentences were recorded using a female voice, when recording and comparing students' voices, male students needed to remember to indicate that their gender is male. As there is a difference of about $100 \mathrm{~Hz}$ between the male and female voices, choosing the wrong gender would have resulted in difficulty in interpreting the pitch curves. This could have been one of the reasons why some male students found the pitch curves on Sptool hard to use.

\section{SUMMARY AND CONCLUSION}

This chapter outlined a number of benefits for students related to the general use of technology in the multi-sensory learning environment known as SEA. Students in the experimental group appeared to gain more confidence in directing their own learning through using Sptool as well as transferring skills learned in the classroom into everyday communication. From a theoretical point of view, the design of SEA directly promotes fluency by initiating and sustaining automatization in a manner compatible with a communicative approach to language teaching. The effectiveness of the SEA environment has been demonstrated by L2 students' superior ability to speak Thai after just 24 hours of face-to-face contact. Indeed, the tasks of learning were made easier by the inclusion of 'low tech' technologies such as the CD-ROM and Sptool. The frequency of interaction and ease of access afforded by the CD-ROM and Sptool had been extremely motivating as on the spot feedback was always available during the beginning stage of learning especially in private study.

One limitation of the study was that it was not possible to closely match the control group with the experimental group as strictly speaking students in the control group studies Thai in a learning Thai as a foreign language context (i.e. in the People's Republic of China) and the students in the experimental group were beginners studying Thai in a second language environment (i.e. in Thailand) even though they were also beginning students of Thai. Though this makes it hard to attribute the learning gains to the environment alone, results obtained here concurred with previous application of the SEA environment in Vietnam with Vietnamese students (Buranapatana, 2007).

The results of this study show that the learning environment known as SEA offered students more than multiple sources of feedback. Most important of all, this environment is a demonstration of how a pronunciation program which involves the learner's intellectual, affective and physical involvement (Morley, 1991, p. 507) can be created and realized.

\section{REFERENCES}

Asher, J. J. (1977). Learning another language through actions: The complete teachers' guide book. Los Gatos, CA: Sky Oaks Productions.

Bancroft, W. J. (1978). The Lozanov method and its American adaptation. Modern Language Journal, 62(4), 167-75.

Boersma, P., \& Weenink, D. (2003). Praat [speech analysis]. Institute of Phonetic Sciences, University of Amsterdam. Retrieved from http://www.praat.org 
Brüll, A. (2003). The acquisition of speech through speech-movement therapy: An exploratory study. The British Journal of Developmental Disabilities, 49(96), 59-65.

Brumfit, C. J. (1984). Communicative methodology in language teaching: The roles of fluency and accuracy. Cambridge, UK: Cambridge University Press.

Chambers, F. (1997). What do we mean by fluency? System, 25(4), 535-44.

Chi, M. T. H., Roy, M., \& Hausmann, R. G. M. (2008). Observing tutorial dialogues

collaboratively: Insights about human tutoring effectiveness from vicarious learning. Cognitive

Science, 32(2), 301-41. doi: 10.1080/03640210701863396

Condon, W. S. (1971). Method of micro-analysis of sound films of behavior. Behavioral

Research Methods and Instrumentation, 2(2), 51-4.

Condon, W. S., \& Ogston, W. D. (1967). A segmentation of behavior. Journal of Psychiatric

Research, 5, 221-35.

Derwing, T. M., Munro, M. J., \& Wiebe, G. E. (1998). Evidence in favor of a broad framework for pronunciation instruction. Language Learning, 48(3). doi: 10.1111/0023-8333.00047

DiJohnson, A., \& Craig, W. N. (1971). An investigation of the verbotonal method with preschool deaf children: A preliminary interim report (pp. 1-64). Harrisburg, PA: Pennsylvania State Dept. of Education.

Egbert, J., Chao, C. C., \& Hanson-Smith, E. (1999). Call environments: Research, practice, and critical issues. Illinois: Teachers of English to Speakers of Other Languages, Inc.

Fraser, H. (2001). Teaching pronunciation: A handbook for teachers and trainers. Sydney, Australia: TAFE NSW Access Division.

Gary, J. O. (1975). Delayed oral practice in initial stages of second language learning. In M. K.

Burt \& H. C. Dulay (Eds.), New directions in second language learning, teaching and bilingual education. (pp. 89-95). Washington, DC: TESOL.

Gatbonton, E., \& Segalowitz, N. (2005). Rethinking communicative language teaching: A focus on access to fluency. The Canadian Modern Language Review, 61(3), 325-53.

Gathercole, S. E., \& Baddeley, A. D. (1993). Working memory and language. Hove, UK:

Lawrence Erlbaum Associates, Ltd.

Guberina, P., \& Asp, C. W. (1981). The verbo-tonal method for rehabilitation people with communication problems. Retrieved from http://www.suvag.com/ang/histoire/autrestextes.html Hinett, K. (1998). The role of dialogue and self assessment in improving student learning. Proceedings the British Educational Research Association Annual Conference, The Queen's University of Belfast.

Hirsh-Pasek, K., Kemler Nelson, D. G., Jusczyk, P. W., Cassidy, K. W., Druss, B., \& Kennedy, L. (1987). Clauses are perceptual units for young infants. Cognition, 26, 269-86.

Hyland, F. (2000). ESL writers and feedback: Giving more autonomy to students. Language Teaching Research, 4(1), 33-54.

Lee, J., Perrachione, T. K., Dees, T. M., \& Wong, P. C. M. (2007). Differential effects of stimulus variability and learners' pre-existing pitch perception ability in lexical tone learning by native English speakers. Paper presented at the Proceedings of International Congress of Phonetic Sciences, Saarbrücken.

Lian, A. (1980). Intonation patterns of French (teacher's book). Melbourne, Australia: River Seine Publications.

Maier, H. W. (2004). Rhythmicity: A powerful force for experiencing unity and personal connections. CYC Online, 66. 
Mandel, D. R., Jusczyk, P. W., \& Kemler Nelson, D. G. (1994). Does sentential prosody help infants to organize and remember speech information? Cognition, 53(2), 155-80. doi:

10.1016/0010-0277(94)90069-8

McCandliss, B. D., Fiez, J. A., Protopapas, A., Conway, M., \& McClelland, J. (2002). Success and failure in teaching the [r]-[1] contrast to Japanese adults: Tests of a Hebbian model of plasticity and stabilization in spoken language perception. Cognitive, Affective, \& Behavioural Neuroscience, 2(2), 89-108.

Morley, J. (1991). The pronunciation component in teaching English to speakers of other languages. TESOL Quarterly, 25(1), 51-74.

Morley, J. (1994). A multidimensional curriculum design. In J. Morley (Ed.), Pronunciation pedagogy and theory (pp. 64-91). Alexandria, VA: TESOL.

Neri, A., Cucchiarini, C., \& Strik, H. (2002). Feedback in computer assisted pronunciation training: When technology meets pedagogy. Proceedings of CALL Conference Professionals and the Future of CALL Research, Antwerp, Belgium.

Oxford, R. L. (1989). Language learning strategies: What every teacher should know. New York, NY: Newbury House/Harper \& Row.

Oxford, R. L., Lavine, Z. R., \& Crookall, D. (1989). Language learning strategies: The communicative approach, and their classroom implications. Foreign Language Annals, 22(1), 1989.

Renard, R. (1985). Structuro-global and autonomy. Revue de Phonétique Appliquée, 73-75, 233. Richard, J. C., \& Rodgers, T. S. (1986). Approaches and methods in language teaching: A description and analysis. Cambridge, MA: Cambridge University Press.

Schneider, W., \& Chein, J. M. ( 2003). Controlled \& automatic processing: Behavior, theory, and biological mechanisms. Cognitive Science, 27, 525-59.

Song, J. H., Skoe, E., Wong, P. C. M., \& Kraus, N. (2008). Plasticity in the adult human auditory brainstem following short-term linguistic training. Journal of Cognitive Neuroscience, 20(10), 1892-902.

Syntrillium. (2002). Cooledit 2000: Syntrillium software. Retrieved from www.syntrillium.com Trubetzkoy, N. S. (1939). Principles of phonology (grundzuge de phonologie, travaux du cercle linguistique de prague) (C. Baltaxe, Trans. 1969 ed.). University of California Press.

Vitanova, G., \& Miller, A. (2002). Reflective practice in pronunciation learning. The Internet TESL Journal, 8(1). Retrieved from http://iteslj.org/Articles/Vitanova-Pronunciation.html Wood, D. (2009). Effects of focused instruction of formulaic sequences on fluent expression in second language narratives: A case study. Canadian Journal of Applied Linguistics, 12(1), 39-57. Zhang, F. (2003). Speech tool [Software]. Canberra, Australia: University of Canberra, Australia. Zhang, F. Z. (2006). The teaching of Mandarin prosody: A somatically-enhanced approach for second language learners. (PhD thesis, University of Canberra, Canberra).

\section{ADDITIONAL READING}

Acton, W. (2000). Some preliminaries to focal stress-based speaking instruction. Journal of Language, Culture and Communication, 2(1), 9-20.

Ambrozic, K. (2003). The meaning of educating according to the Verbotonal method for the successful integration of deaf and hard of hearing children into secondary school Arnold, J. (2000). Seeing through listening comprehension exam anxiety. TESOL QUARTERLY, 34(4), 777-86. 
Bransford, J. D., Brown, A. L., \& and Cocking, R. R. (Eds.). (2000). How people learn: Brain, mind, experience, and school. Washington, D.C.: National Academy Press.

Briguglio, C. (2000). Language and cultural issues for English as a second/foreign language students. Higher Education in Europe, 25(3), 425-34.

Burgess, J., \& Spencer, S. (2000). Phonology and pronunciation in integrated language teaching and teacher education. System, 28(2), 191-215.

Cucchiarini, C., Strik, H., \& Boves, L. (2000). Quantitative assessment of second language learners' fluency by means of automatic speech recognition technology. J. Acoust. Soc. Am, 107(2), 989-99.

Dornyei, Z., \& \& Kormos, J. (2000). The role of individual and social variables in oral task performance. Language Teaching Research, 4, 275-300.

Ejzenberg, R. (2000). The juggling act of oral fluency: A psycho-sociolinguistic metaphor. In H. Riggenbach (Ed.), Perspectives on fluency (pp. 287-314): Michigan: The University of Michigan Press.

Fraser, H. (2000). Coordinating improvements in pronunciation teaching for adult learners of English as a second language. Canberra: DETYA.

Freed, B. F. (2000). Is fluency, like beauty, in the eyes (and ears) of the beholder? In H. Riggenbach (Ed.), Perspectives on fluency (pp. 243-65). Michigan: The University of Michigan Press.

Gandour, J., Wong, D., Hsieh, L., Weinzapfel, B., Van Lancker, D., \& \& Hutchins, G. (2000). A cross-linguistic pet study of tone perception. Journal of Cognitive Neuroscience, 12, 207-22.

Gill, C. (2000). Getting language learners to â€ open upâ€ $€^{\text {TM }}$. Australian Language Matters, 8(2), 7-8.

Goh, C. C. M. (2000). A cognitive perspective on language learners' listening comprehension problems. System, 28, 55-75.

Grant, L. (2000). Form to meaning: Bridges in pronunciation teaching. TESOL Matters, Vol 9. Hardison, D. M. (2000). The neurocognitive foundation of second-language speech: A proposed scenario of bimodal development. In B. Swierzbin, F. Morris, M. E. Anderson, C. A. Klee \& E. Tarone (Eds.), Social and cognitive factors in second language acquisition (pp. 312-25).

Somerville, MA: Cascadilla Press.

Jenkins, J. (2000). The phonology of English as an international language. New York: Oxford University Press.

Kerr, J. (2000). Articulatory setting and voice production: Issues in accent modification.

Prospect:A Journal of Australian TESOL, 15(2), 4-15.

Kerstjens, M., \& Nery, C. (2000). Predictive validity in the IELTS test. IELTS research reports, 3, 85-108.

Koponen, M., \& Riggenbach, H. (2000). Overview: Varying perspectives on fluency. In H. Riggenbach (Ed.), Perspectives on fluency (pp. 5-24). Michigan: The University of Michigan Press.

Larsen-Freeman, D. (2000). Techniques and principles in language teaching. Oxford: Oxford University Press.

Lennon, P. (2000). The lexical element in spoken second language fluency. In H. Riggenbach (Ed.), Perspectives on fluency (pp. 25-42). Michigan: The University of Michigan Press.

Linda, G. (2000). Form to meaning: Bridges in pronunciation teaching. TESOL Matters, 9(6). Miller, S. (2000). Looking at progress in a pronunciation class. TESOL Matters, 10(2). 
Mora, F. C. (2000). Foreign language acquisition and melody singing. ELT Journal, 54(2), 14652.

Morley, L., Leonard, D., \& David, M. (2002). Variations in vivas: Quality and equality in british phd assessments. Studies in Higher Education, 27(3), 263.

Pennington, M. C., \& Ellis, N. C. (2000). Cantonese speakers' memory for English sentences with prosodic cues. Modern Language Journal, 84(3), 372-89.

Segalowitz, N. (2000). Automaticity and attention skill in fluent performance. In H. Riggenbach (Ed.), Perspectives on fluency (pp. 200-19). Michigan: The University of Michigan Press.

Syntrillium. (2002). Cooledit 2000: Syntrillium software. Retrieved from www.syntrillium.com Toohey, K. (2000). Learning English at school: Identity, social relations and classroom practice. Clevedon, England: Multilingual Matters.

Toohey, S. (2000). Designing courses for higher education: Buckingham The Society for Research into Higher Education and Open University.

Tse, L. (2000). Student perceptions of foreign language study: A qualitative analysis of foreign language autobiographies. The Modern Language Journal, 84(1), 69-84. doi: 10.1111/00267902.00053

Wennerstorm, A. (2000). The role of intonation in second language fluency. In H. Riggenbach (Ed.), Perspectives on fluency (pp. 102-27). Michigan: The University of Michigan Press. Witte, A. E. (2000). Improving pronunciation through scripts. TESOL Matters, 10(3).

\section{KEY TERMS AND DEFINITIONS}

Suprasegmental: Some phonemes cannot be easily analyzed as distinct segments, but rather belong to a syllable or even word. Such "suprasegmentals" include tone, stress, and prosody. Segmental: describes the discrete elements of sequential speech, as consonants and vowels. Formulaic language: In this chapter, recurring multiword chunks in the speech of native speakers in particular contexts are defined as formulaic utterances.

SUVAG II: The SUVAG II is an auditory training unit for the rehabilitation of hard of hearing subjects and of those with small hearing impairment. From an enormous number of frequency characteristics which can be synthetised with this unit, it is possible to choose the one which is optimal for the hard of hearing subject. With this optimal field the intelligibility of speech is improved and persists even later in unaided listening. Furthermore, the unit is particularly useful in determining and fitting the individual hearing aid

Verbo-tonal method of phonetic correction: Each language has its own intonation, rhythm and sounds. The Verbo-tonal method for phonetic correction helps you to recognize these factors that make up the sound of a language and so improve your pronunciation. 